\title{
O PROFESSOR LUIS ANTONIO DA GAMA E E SILVA NA CÁTEDRA DE DIREITO INTERNACIONAL PRIVADO
}

Em sessão solene da Congregação, realizada em 10 de junho de 1953, tomou posse da Cátedra de Direito Internacional Privado o Prof. Luis Antonio da Gama e Silva.

0 novo lente da Academía foi introduzido no recinto por uma comissão nomeada pelo Diretor da Faculdade.

Em nome da Congregação falou o Prof. Dr. Miguel Reale, que enalteceu a obra cultural do jovem mestre, pondo em realce o brilho e a segurança revelados, mais uma vez, durante as provas do concurso.

\section{O DISCURSO DO NOVO GATEDRÁTICO}

— "Bem podeis imaginar, eminentes mestres da Congregação da Faculdade de Direito da Universidade de São Paulo, a profunda e intensa emoção, que me domina, ao ser elevado, pela vossa sábia decisão, ao alto cargo de professor catedrático de direito internacional privado desta nossa querida Faculdade.

Se algum sonho acalentei, em constante e piedosa vigilia, se algum ideal me animou sempre, desde aquele dia em que, há quasi vinte anos, deixei as venerandas e tradicionais arcadas do velho convento franciscano, que então se destruia para ceder lugar ao monumento arquitetônico, que, hoje, todos contemplam e admiram, foi o del um dia voltar ao vosso convívio para, como professor de direito, legar às 
gerações do porvir os exemplos admiráveis e os sábios e perenes ensinamentos, que recebi dos mestres que, ontem, como agora, dignificam e honram, enaltecem e ilustram a cultura jurídica de nossa pátria e o ensino superior do país.

Embora minha vida, por muitos anos, se desenvolvesse à margem daquele sonho antigo e do nobre ideal, que nunca envelheceu, um dia bati às vossas portas e me acolhestes, concedendo-me o título de docente livre de direito internacional privado. E no exercício das atribuições, que me confiastes, ocupando o lugar de um professor ilustre, mestre insubstituivel, a quem, há dois dias, laureastes com a mais alta dignidade universitária, o professor emérito Antonio de Sampaio Doria, tenho a consciência de que não deslustrei o posto a que me alçastes, de que não desmerecí da confiança em mim depositada, de que não faltei ao cumprimento do dever.

Neste momento, ao ser por vós empossado no cargo de professor catedrático de direito internacional privado, permitindo-me compor convosco nossa doutíssima Congregação, após disputado concurso de títulos e provas, bem compreendeis minha intensa emoção e sentís meu júbilo profundo, porque vejo, neste ato, concretizado aquele sonho e realizado o ideal que me seduziu e foi, por longo tempo, minha preocupação, a mais constante. Honra-me sobremaneira ver Costa Carvalho e Helio Tornaghi, da Faculdade de Direito aquí, ao vosso lado, os ilustres professores Luis Antônio da da Universidade do Brasil, Pedro Lins Palmeira, da Faculdade de Direito de Recife e Cândido Naves, da Faculdade de Direito da Universidade de Minas Gerais, cuja presença a esta solenidade muito agradeço. Aquí está, também, minha esposa, companheira incansável de tantas lutas, contribuindo, eficazmente, para nossa vitória comum; encontro, também, meu irmão mais jovem, ainda estudante de direito a me recordar os que me são mais caros, só me restando lamentar, grande mágua sem remédio, a ausência de meu saudoso pai, cuja perene lembrança me inspira e guia. 
Bem sei, eminentes mestres, minhas senhoras e meus senhores, a responsabilidade que me advém da honrosa investidura, principalmente quando contemplo, descerrando os véus do passado, os nomes ilustres que, nesta Faculdade, que tanto queremos e admiramos, ensinaram aos moços do Brasil o direito internacional privado.

Ciência jurídica das mais novas, ainda em constantes transformações e perpétua evolução, com seus controvertidos problemas a desafiar o senso dos juristas de todo o mundo, se é certo que, há pouco mais de vinte e cinco anos, se erigiu em disciplina autônoma nos cursos jurídicos do país, durante longo tempo foi lecionada - se a tanto o ano letivo bastasse - como parte integrante de outras cadeiras do curso de bacharelado. E nesta Faculdade, no século passado e em nossa época, Américo Brasiliense, Oliveira Lima, Oliveira Coutinho, José Mendes, Souza Carvalho, Sampaio Doria e, em carater interino, este dedicado e bondoso Pinto Pereira, honraram e elevaram a cátedra que, agora, me é entregue. Tão sòmente a evocação dêstes mestres, os dois últimos meus professores do curso jurídico, está a demonstrar o gráu do encargo que assumo perante vós e a mocidade estudiosa de nossa terra.

A nós professores - e professores de direito - cabe, na hora presente, acima de simples função cultural, de mero trabalho educativo, importante missão social e moral, porque a nós está entregue a formação de uma preciosa juventude, sempre incuieta e preocupada com os grandes problemas que afligem o homem e a humanidade inteira. São almas em floração, espíritos que despontam para a vida, contemplando as tragédias dos nossos dias, o culto da força e da incompetência, dos valores negativos e da irresponsabilidade, da corrupção e da improbidade. E é neste panorama de dias incertos e de um futuro intranquilo, e é neste ambiente ameaçador, que a ação do mestre de direito se deve fazer sentir e projetar-se, conduzindo as gerações jovens à conquista de um melhor porvir. 
Não nos esqueçamos que a verdadeira conciência jurídica, que impõe renúncias constantes e constante desinterêsse na pesquisa da verdade, vai sendo dominada por um utilitarismo sedutor, mas traiçoeiro, a pregar a derrocada da verdadeira ordem jurídica e a destruição dos principios fundamentais e eternos do direito. E nada melhor do que a cátedra onde o mestre, pela lição e pelo exemplo, mais pelo exemplo do que pelos ensinamentos que prega e difunde, pode alertar os espíritos moços contra as tentações doiradas de doutrinas perigosas e sistemas aviltantes, que se opõem à própria dignidade da pessoa humana.

Louvado seja o eminente pensador argentino que ensinou, em memorável lição, não haver pior mestre do que o animado por simples fins lucrativos e interesseiros, nem pior pedagogia do que a praticada sem amor. A sociedade entrega o jovem ao mestre, como ao jardineiro a semente, para que naquele germinem os sentimentos e desta brotem as flores. E' preciso saber formar canteiros humanos, regálos, protegê-los, escorá-los, classificá-los, arancando-lhes as mazelas, para que da escola desabroche, bela e louçã, a mais admirável flor do universo: o homem.

E o homem, na expressão do mestre sem igual, é uma criatura animada pelo sopro divino, e todo aquêle que tem a conciência de o possuir se não pode submeter ao dominio arbitrário dos outros. Os que se deixarem vencer, pelo interêsse ou pelo medo, pela sedução dos poderosos ou corrupção dos venais, pela ignorância ou pela traição consentida, se amesquinham e se aniquilam, sufoćando as liberdades e destruindo a ordem jurídica e social, esquecidos de que "com homens pequenos nada de grande se pode fazer."

Acredito, porisso, eminentes mestres, porque êste foi o Credo que me ensinaste nesta Faculdade, quando me formastes soldado da lei, que sòmente com ela, para ela e sob ela podemos ter uma vida digna, livre de temores, interna e internacionalmente. Porque nesta Faculdade, cujas tradições imorredoras de amor à liberdade, de pregação do di- 
reito e de defesa da justiça são o seu melhor apanágio, seus mestres e seus discipulos, há mais de um século, vêm nessa trilogia magnífica a razão de ser de sua própria existência. E por aí medimos a extensão do trabalho que cabe aos professores de direito, notadamente nesta fase em que grandes transformações econômicas e sociais abalam os alicerces da ordem jurídica contemporânea, ameaçando sacrificar a liberdade, a dignidade, a personalidade do ser humano.

Foram êsses, entre tantos outros, alguns dos ensinamentos que recebi nesta Faculdade e aos quais tenho procurado ser fiél e que prometo sabê-lo transmitir, com proveito, aos jovens estudantes desta casa.

Sendo por vós recebido, neste instante, pela palavra afetuosa e amiga do ilustre professor Miguel Reale, a êste eminente mestre, jurista de escol, espírito sempre voltado às investigações da filosofia jurídica, nome que honra nossa cultura e que, pelos seus méritos, atravessou as lindes da pátria para, no estrangeiro, se alçar como notável expressão de nosso saber jurídico, a Miguel Reale, meu colega na turbulenta e inquieta turma, que viveu nas Arcadas de 1930 a 1933, meu maior e melhor reconhecimento. Suas palavras eloquentes e amigas tocaram profundamente a meu coração e, assim, a êle e a todos vós sou eternamente agradecido.

Senhor diretor, senhores professores:

Nesta cerimônia, soleníssima pela sua expressão e significado, porque recebeis em vosso seio um novo companheiro, que, como vós outros, tem vivido pela sua Faculdade, procurando sempre elevar, cada vez mais, seu nome glorioso, ao lado de meu perene reconhecimento, desejo testemunhar-vos, mais uma vez, o firme propósito de ,no culto de suas mais caras e maiores tradições, sempre serví-la e amá-la, como um filho, comunicando a todos os que querem a esta terra bendita, que a imágem do Cruzeiro ilumina e protege, que, neste Templo do Direito, um só e eterno pensamento o anima e orienta, com os seus mestres e os seus 
discípulos: "Com a lei, pela lei, dentro da lei, porque fora da lei não há salvação."

DADOS BIO-BIBLIOGRÁFICOS DO PROF. LUÍS ANTONIO DA GAMA E SILVA

Nasceu o novo catedrático de Direito Internacional Privado, na cidade de Mogí-Mirim, dêste Estado, a 19 de maio de 1913, sendo filho do dr. Acrisio da Gama e Silva, que foi magistrado em São Paulo, e de D. Ana da Gama e Silva.

$\mathrm{Fez}$ os estudos primários em sua terra natal e os prímeiros exames do curso secundário no "Ginásio Culto à Ciência", de Campinas, matriculando-se, depois, no "Ginásio Diocesano de Santa Maria", de Campinas, onde concluiu o curso ginasial em 1929, como dos primeiros de sua turma.

Após as provas vestibulares, matriculou-se no primeiro ano do curso de bacharelado, desta Faculdade, em 1930, tendo tomado parte ativa em todos os movimentos cívicos que, após seu ingresso, envolveram os alunos da Academia de Direito, assim como se dedicou à política e imprensa aćadêmicas. Recebeu o gráu de bacharel em ciências jurídicas e sociais no dia 5 de janeiro de 1934 .

Dedicou-se, desde logo, à advocacia e à política, filiado ao Partido Republicano Paulista e, como jornalista, ingressou no "Correio Paulistano". Em 1935, durante alguns meses, foi promotor público interino, em Mogí-Mirim. Além de advogado e jornalista, foi o professor Luis Antonio da Gama e Silva professor do curso secundário, tendo lecionado no "Liceu Pan-Americano", "Colégio Carlos Gomes", "Liceu Nacional Rio Branco", mais tarde "Colégio Rio Branco", dedicando-se ao ensino da língua portuguesa : e da lógica.

Durante o período ditatorial se manteve afastado da política, militando, todavia, na resistência contra o Estado Novo. Como representante da indústria, foi nomeado juiz. 
do Tribunal de Impostos e Taxas do Estado de São Paulo, função esta para a qual tem sido reconduzido desde sua primèira designação, tendo feito parte de uma comissão encarregada de rever e consolidar o direito tributário do Estado de São Paulo.

Em novembro de 1944 prestou, nesta Faculdade, concurso para a docência-livre de Direito Internacional Privado, defendendo, com brilho, sua tese sobre a "Ordem Pública em Direito Internacional Privado". Tendo sido aprovado, foi nomeado livre-docente em 11 de dezembro de 1944, quando recebeu o gráu de doutor em direito. Em abril de 1945, com o afastamento do professor catedrático dr. Antônio de Sampaio Doria, então nomeado Juiz do Superior Tribunal Eleitoral, o prof. Luis Antônio da Gama e Silya, foi nomeado para exercer, interinamente, o cargo de professor catedrático de Direito Internacional Privado, onde se manteve, quasi ininterruptamente, até a aposentação do prof. A. de Sampaio Doria, em 24 de janeiro de 1952. Nesta data, foi nomeado professor catedrático interino de Direito Inter'nacional Privado da Faculdade de Direito da Universidade de São Paulo.

Com a volta do país ao regime da liberdade, contribaiu o professor Luis Antonio da Gama e Silva para a reorganização do Partido Republicano, foi candidato, pela legenda U.D.N. — P.R., a deputado à Assembléia Constituinte q 1946 e passou a redator-chefe do "Correio Paulistano" e diretor da "S. A. Empresa do Correio Paulistano" Em 1949, por divergências internas em seu partido, se desligou do mesmo, afastando-se da política militante e deixando a direção do "Correio Paulistano".

Em abril e maio de 1953 prestou concurso para professor catedrático de Direito Internacional Privado do curso de bacharelado da Faculdade de Direito da Universidade de São Paulo, tendo sido classificado, unânimemente, em primeiro lugar, com a média de 9,75, e nomeado professor catedrático da disciplina por decreto de 27 de Maio de 1853. Sua tese de concurso - "As qualificações em Direito Inter- 
nacional Privado" - constituiu notável estudo sôbre êsse importante problema da ciência dos conflitos de leis no espaço e mereceu de toda a banca examinadora, constituida dos professores Vicente Rao, Lino Leme, Amilcar de Castrc e Albérico Fraga, e desembargador Antão de Morais os mais eloquentes elogios. Tomou posse do cargo, em sessão da Congregação, a 8 de junho de 1953.

O professor Luis Antônio da Gama e Silva é consultor jurídico do Sindicato da Indústria da Energia-Hidro-Elétrica no Estado de São Paulo, da Associação Paulista de Empresas de Serviços públicos e da Associação de Usineiros de São Paulo. E' diretor do Centro das Industrias do Estado de São Paulo, tendo tomado parte, como delegado de São Paulo, na II Conferência Nacional das Classes Produtoras, realizada em Araxá, em 1949, e na Primeira Reunião Pỉenária da Indústria Nacional, em maio de 1953, em São Paulo, onde deu valiosa contribuição ao estudo e solução dos problemas ligados l̀̀ energia elétrica e direito fiscal.

Pertence, também, o prof. Luiz Antônio da Gama e Silva à Associação Brasileira de Direito Internacional, ao Instituto dos Advogados de São Paulo e ao Instituto Hispano-Luso-Americano de Direito Internacional, sendo, atualmente, Secretário Geral desta organização internacional. Como representante do Brasil, tomou parte no II Congresso Hispano-Luso-Americano de Direito Internacional realizado em São Paulo, em outubro deste ano, tendo sido eleito Secretário Geral deste certame jurídico. E' também diretor do Instituto de Organização Racional do Trabalho (I. D. O. R. T.).

Além de artigos jurídicos publicados em jornais e révistas especializadas, o professor Luiz Antonio da Gama e Silva publicou: “A Ordem Pública em Direito Internacional Privado", São Paulo, 1944; “As Qualificações em Direito Internacional Privado", São Paulo, 1952; "As leis penais nas relações jurídicas internacionais", São Paulo, 1943. 